\title{
Strategi Komunikasi Pembangunan Pemerintah Kabupaten Bojonegoro dalam Menerapkan Nawacita dan Tujuan Pembangunan Berkelanjutan
}

\section{Development Communication Strategy by Bojonegoro District Government on Applying Nawacita and Sustainable Development Goals}

\author{
Rizky Wulan Ramadhani*), Edy Prihantoro
}

Fakultas Komunikasi, Universitas Gunadarma, Depok 16451, Indonesia

${ }^{*}$ E-mail korespondensi: rrizkywulan@gmail.com

Diterima: 30 Desember 2019 | Direvisi: 22 Juni 2020 | Disetujui: 29 Juni 2020 | Publikasi online: 10 Juli 2020

\begin{abstract}
Sustainable Development Goals (SDGs) is an agenda declared by United Nations on 2015 that should be achieved on 2030. Nawacita is a series of programs proposed by Jokowi-JK during 2014-2019 period which includes ways to achieved SDGs in Indonesia. The aim of this research is to know the development communication strategies used by Bojonegoro District Government on communicating Nawacita and SDGs. This research uses qualitative methodology by doing interview and documentation. Key informant on this research is Kang Yoto, Regent of Bojonegoro on 2008 2018 period. The result of this research is that Bojonegoro District Government uses strategies based on media used, instructional design strategy, marketing strategy, and participatory strategy. Strategies used are effective to persuade Bojonegoro people to support the achievement of SDGs and to inform public about SDGs. These strategies can be used by another local government by considering condition of their people.
\end{abstract}

Keywords: Development Communication, Local Governance, Strategic Communication, Sustainable Development Goals

\begin{abstract}
ABSTRAK
Tujuan Pembangunan Berkelanjutan (TPB) atau Sustainable Development Goals (SDGs) adalah agenda yang dideklarasikan dalam majelis umum Perserikatan Bangsa-Bangsa (UN) pada tahun 2015 dan harus diraih bersama pada 2030. Nawacita adalah sembilan program yang diajukan Jokowi-JK selama periode 2014-2019. Penelitian ini bertujuan untuk mengetahui strategi-strategi komunikasi pembangunan yang dipakai Pemerintah Kabupaten Bojonegoro dalam mengkomunikasikan Nawacita dan SDGs. Penelitian ini menggunakan metodologi kualitatif dengan metode wawancara dan dokumentasi. Key informant dalam penelitian ini adalah Kang Yoto, Bupati Bojonegoro periode 2008-2018 dan dokumentasi dari berbagai sumber. Hasil penelitian ini adalah Pemkab Bojonegoro menggunakan strategi yang didasarkan pada media yang dipakai, strategi desain instruksional, strategi pemasaran, dan strategi partisipatori. Strategi yang dipakai efektif untuk mengajak masyarakat Bojonegoro sekaligus memberi informasi bagi publik. Pemerintah daerah yang lain bisa menerapkan strategi yang sama dengan mempertimbangakan kondisi masyarakatnya.
\end{abstract}

Kata Kunci: Komunikasi Pembangunan, Komunikasi Strategis, Pemerintahan Daerah, SDGs

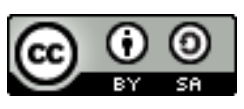

Content from this work may be used under the terms of theCreative Commons Attribution-ShareAlike 4.0 International. Any further distributionof this work must maintain attribution to the author(s) and the title of the work, journal citation and DOI.

Published under Department of Communication and Community Development Science, IPB University and in association with Forum Komunikasi Pembangunan Indonesia and Asosiasi Penerbitan Jurnal Komunikasi Indonesia.

E-ISSN: 2442-4102 | P-ISSN: 1693-3699 


\section{PENDAHULUAN}

Tujuan Pembangunan Berkelanjutan (TPB) atau Sustainable Development Goals (SDGs) adalah agenda yang berhasil disahkan pada pertemuan tahunan Perserikatan Bangsa-Bangsa (PBB) yang ke70 September 2015 lalu. Agenda tersebut, dengan 17 Tujuan Pembangunan Berkelanjutan (TPB) sebagai intinya, adalah sebuah panduan untuk menangani tantangan yang paling mendesak di duniatermasuk mengakhiri kemiskinan dan membawa kemakmuran ekonomi, inklusi sosial, keberlanjutan lingkungan dan perdamaian dan pemerintahan yang baik bagi setiap negara dan semua orang pada tahun 2030 (Kestin et al., 2017). SDGs disepakati oleh 193 kepala negara, termasuk Indonesia yang diwakili Wakil Presiden Republik Indonesia, Jusuf Kalla.

SDGs merupakan kelanjutan Millennium Development Goals (MDGs) yang disepakati oleh negara anggota PBB pada tahun 2000 dan berakhir pada akhir tahun 2015 (Panuluh \& Fitri, 2016). MDG memiliki delapan tujuan pembangunan millennium, yakni menanggulangi kemiskinan dan kelaparan, mencapai pendidikan dasar untuk semua, mendorong kesetaraan gender dan pemberdayaan perempuan, menurunkan angka kematian anak, meningkatkan kesehatan ibu, memerangi HIV/AIDS, malaria, dan penyakit menular lainnya, memastikan kelestarian lingkungan hidup, mengembangkan kemitraan global untuk pembangunan (Lisbet, 2013).

Keefektifan MDGs telah menjadi subjek perdebatan yang cukup besar (ICLEI, 2015). Beberapa pihak menyatakan bahwa MDGs telah mempelopori gerakan internasional dan mampu melawan kemiskinan ekstrim sebesar 50\% secara global, namun beberapa pihak juga mengkritisi pelaksanaan MDGs yang hanya diaplikasikan di negara berkembang. Belajar dari penerapan MDGs, SDGs akan berlaku secara universal untuk semua negara PBB, dan lebih komprehensif dan ambisius dari MDGs (ICLEI, 2015).

Prinsip-prinsip pelaksanaan TPB atau SDGs adalah Universality, Integration, dan No One Left Behind (Wahyuningsih, 2016). Universality memiliki arti bahwa SDGs dilaksanakan oleh negara maju maupun negara berkembang. Integration memiliki arti SDG dilaksanakan secara terintegrasi antara dimensi sosial, ekonomi dan lingkungan. No One Left Behind memiliki arti bahwa pelaksanaan SDG harus memberi manfaat bagi semua, terutama yang termarginalkan dan pelaksaan SDGs harus melibatkan berbagai pemangku kepentingan. SDGs membawa 5 prinsip-prinsip mendasar yang menyeimbangkan dimensi ekonomi, sosial, dan lingkungan, yaitu 1) People (manusia), 2) Planet (bumi), 3) Prosperity (kemakmuran), 4) Peace (perdaiaman), dan 5) Partnership (kerjasama) (Panuluh \& Fitri, 2016). Kelima prinsip tersebut menaungi 17 tujuan dan 169 target SDGs yang saling terhubung dan terintegrasi.

Pemerintah Indonesia pada era Joko menyatakan bahwa Indonesia berkomitmen untuk mengimplementasikan Suistanable Development Goals dengan mengadopsi hasil kesepakatan Suistanable Development Goals melalui prinsip Nawa Cita yang dituangkan dalam rencana pembangunan jangka menengah negara (RPJMN) 2015-2010 (Arianto, 2019). Terdapat beberapa keselarasan poin antara Nawacita dengan SDGs. Dalam hal pembangunan manusia, pembangunan ekonomi dan keberlanjutan ekologi dan konservasi keduanya dapat sejalan selaras (Arianto, 2019). Nawacita yang menjadi visi-misi Jokowi-JK selama periode 2014-2019 berisi sembilan program yang mendukung tercapainya SGDs.

Sejak SDGs disahkan tahun 2015, Pemerintah Daerah Kota/Kabupaten diyakini berperan sentral dalam pelaksanaan dan pencapaian SDGs. Pemerintah daerah memiliki kelebihan antara lain adalah (a) berada lebih dekat dengan warganya; (b) memiliki wewenang dan dana; (c) dapat melakukan berbagai inovasi; serta (d) ujung tombak penyedia layanan publik dan berbagai kebijakan serta program pemerintah (Hoelman et al., 2016). Peran pemerintah dalam menerapkan SDGs adalah dengan melakukan lokalisasi yang dimaknai sebagai proses untuk menerapkan dan mengawasi strategi di level lokal yang akan berdampak pada proses pencapaian SDGs secara nasional. Lokalisasi melibatkan berbagai mekanisme, alat, inovasi, media dan proses untuk menerjemahkan secara efektif agenda pembangunan menjadi hasil-hasil di level lokal (Reddy, 2016). Lokalisasi dilakukan dengan menyesuaikan budaya lokal yang berbeda sesuai dengan daerah masing-masing. Dalam konteks ini, budaya lokal yang berbeda, termasuk masyarakat adat dan otoritas tradisional, minoritas dan migran, bisa digunakan sebagai narasumber dalam hal mengembangkan kebijakan lokal, yang pada akhirnya akan memastikan bahwa seluruh proses dipandang sebagai partisipatif, sah, dan kredibel oleh masyarakat sekitar (Reddy, 2016). 
Penerapan SDGs memerlukan kerjasama yang kuat dan efektif antara pemerintah kabupaten, provinsi dan nasional, serta aktor lain termasuk organisasi masyarakat dan sektor privat (Guha \& Chakrabarti, 2019). Kerjasama antara berbagai pihak dilakukan atas dasar kepercayaan dengan memaksimalkan peran masing-masing serta interaksi antar berbagai stakeholder. Untuk menumbuhkan kepercayaan stakeholder, pemerintah daerah harus memastikan prosedur yang transparan dan bertanggung jawab sesuai dengan arahan pemimpin. Dukungan kepemimpinan politik diketahui sangat penting untuk pemerintah daerah yang responsive, reflektif, dan akuntabel dan kemungkinan kerjasama yang sukses tidak akan terjadi tanpa adanya kepemimpinan (Guha \& Chakrabarti, 2019).

Sebagian pemerintah daerah telah menentukan target strategis untuk mencapai SDGs tergantung pada dukungan yang diberikan oleh pemerintah nasional dan stakeholder (Morita et al., 2019), namun banyak stakeholder yang tidak memiliki pengetahuan, dana, sumber infrastruktur sehingga menghambat proses pencapaian SDGs. Sebagian pemerintah daerah memiliki kekurangan kapasitas untuk melaksanakan implementasi, tetapi kerangka peraturan kuat ada melalui Peraturan Gubernur (Morita et al., 2019). Melalui peraturan gubernur atau peraturan bupati, beberapa daerah menunjukkan komitmennya dalam melaksanakan SDGs melalui pendekatan yang lebih spesifik dan disesuaikan dengan kondisi daerah. Namun pendekatan tersebut masih kurang efektif karena Indonesia menghadapi tantangan terutama di level lokal. Nilai rendah dalam level lokal sebagian besar disebabkan oleh kurangnya sistem koordinasi yang melibatkan berbagai stakeholder dan tidak memadainya kapasitas, pengalaman, sumber dan data untuk menerapkan dan mengevaluasi penerapan SDGs (Morita et al., 2019).

Penelitian Sudagung et al., (2019) meneliti tentang peran Pemerintah Provinsi Kalimantan Barat dalam mencapai target SDGs di bidang pendidikan dengan membangun fasilitas pendidikan yang terjangkau di setiap jenjang pendidikan. Melalui program tersebut, Pemerintah Provinsi Kalimantan Barat mewajibkan masyarakatnya untuk bersekolah dari SD hingga SMP dan sederajat. Selain itu, Pemerintah Provinsi Kalimantan Barat juga mencanangkan program peningkatan pemberantasan Buta Aksara dan Percepatan pencapaian wajib belajar 9 tahun dan perintisan wajib belajar 12 tahun.

Salah satu pemerintah daerah yang telah menerapkan SDGs pembangunan manusia dan Nawacita adalah Pemerintah Kabupaten Bojonegoro (Pemkab Bojonegoro) di bawah pimpinan Suyoto atau yang biasa dipanggil Kang Yoto yang memimpin Kabupaten Bojonegoro periode 2008 - 2018. Pada bulan Maret 2016 lalu, Pemkab menyatakan bawa secara resmi Bojonegoro memulai SDGs ditandai dengan pemukulan gong oleh Bupati Bojonegoro, Suyoto pada kegiatan yang dilaksanakan oleh World Bank (Panuluh \& Fitri, 2016). Pemkab Bojonegoro kemudian mengeluarkan Keputusan Bupati Bojonegoro Nomor 188/1171/KEP/412.11/2016 tentang Gugus Tugas Pelaksana Tujuan Pembangunan Berkelanjutan (Sustainable Development Goals/ SDGs) Kabupaten Bojonegoro.

Pelaksanaan SDGs di Bojonegoro pernah diteliti dalam Analisa Sustainable Development Goal's Kabupaten Bojonegoro Tahun 2017. Penelitian ini dilakukan untuk mengetahui posisi awal pembangunan berkelanjutan/SDG's Kabupaten Bojonegoro. Berdasarkan penelitian ini, Kabupaten Bojonegoro akan segera memiliki kelembagaan khusus berikut unit kerja yang akan menangani SDGs, menyusun Rencana Aksi Tujuan Pembangunan Berkelanjutan (Renaksi TPB) Kabupaten Bojonegoro untuk Tahun 2018-2022, mengembangkan sistem "One Data" untuk menangani pengelolaan data dalam rangka optimalisai pelaksanaan TPB/SDG's, mengintensifkan koordinasi antar stakeholder yang terlibat dalam pelaksanaan TPB/SDG's dan menerbitkan regulasi yang mengatur pelaksanaan SDGs.

Pencapaian Nawacita dan SDGs oleh Pemkab Bojonegoro tidak lepas dari peran masyarakatnya yang ikut aktif dalam kegiatan pembangunan. Peran masyarakat sangat penting dalam proses pembangunan karena keterlibatan aktif atau partisipasi masyarakat tersebut dapat berarti keterlibatan dalam penentuan arah, strategi dan kebijaksanaan pembangunan yang dilakukan oleh pemerintah (Surahmi \& Farid, 2018). Dukungan masyarakat terhadap pelaksanaan pembangunan merupakan salah satu faktor yang dapat menentukan keberhasilan dan kegagalan setiap program pembangunan (Surahmi \& Farid, 2018). Dalam meningkatkan peran masyarakat, Pemkab Bojonegoro melakukan strategi komunikasi pembangunan untuk memfasilitasi masyarakat yang ingin terlibat secara aktif dalam proses pembangunan, sehingga penelitian ini bertujuan untuk mengetahui strategi-strategi komunikasi pembangunan yang dipakai Pemerintah Kabupaten Bojonegoro dalam mengkomunikasikan Nawacita dan SDGs. 


\section{Strategi Komunikasi Pembangunan}

Strategi pada hakekatnya adalah perencanaan (planning) dan manajemen untuk mencapai suatu tujuan (Nurdin, 2013). Menurut Quebral komunikasi pembangunan adalah komunikasi yang dilakukan untuk melaksanakan rencana pembangunan suatu negara (Astuti, 2017). Komunikasi pembangunan dapat dicerminkan oleh suatu komunikasi yang berorientasi pada: 1) Perilaku/edukasi, 2) Kesejahteraan dan 3) Menuju ke arah kemajuan masyarakat (Wibowo et al., 2011). Untuk menggerakkan masyarakat agar ikut terlibat aktif dalam pembangunan maka dibutuhkan strategi komunikasi yang baik oleh seorang pemimpin (Surahmi \& Farid, 2018).

Strategi komunikasi pembangunan dapat dimaknai sebagai perencanaan komunikasi dan manajemen komunikasi dalam penyebaran pesan-pesan pembangunan guna mengajak masyarakat terlibat dalam proses pembangunan. Arti penting strategi komunikasi dalam kaitannya dengan pembangunan di suatu negara ini dimaknai oleh Effendy (2010), mempunyai fungsi: (1) menjembatani "cultural gap" akibat kemudahan yang diperoleh dan kemudahan dioperasionalkannya media massa yang begitu kuat pengaruhnya, dan jika dibiarkan akan merusak tataran budaya bangsa sendiri dan (2) mensosialisasikan pesan komunikasi yang bersifat informatif, persuasif, dan instruktif secara sistematik kepada sasaran guna memperoleh hasil yang optimal (Fajri et al., 2018).

Dalam hal penerapan Nawacita untuk mencapai SDGs, strategi komunikasi pembangunan dilakukan untuk mengajak masyarakat agar mau terlibat dalam proses pembangunan berkelanjutan. Terdapat empat strategi komunikasi yang dikemukakan oleh Academy for Educational Development (AED) yaitu:

\section{Strategi yang Didasarkan pada Media yang Dipakai (Media Based Strategy)}

Media komunikasi yang dipilih hendaknya disesuaikan dengan tujuan komunikasi dan keadaan sosial budaya masyarakat setempat, sehingga pesan yang disampaikan lebih mudah diterima (Tahoba, 2011). Media yang dipakai bisa menggunakan media cetak, media elektronik, media sosial maupun komunikasi antarpribadi. Untuk masyarakat luas, pesan sebaiknya disalurkan melalui media massa, misalnya surat kabar atau televisi, dan untuk kelompok tertentu digunakan saluran komunikasi kelompok (Wijaya, 2015). Strategi ini memang merupakan teknik yang paling mudah, paling popular, dan tentunya yang paling kurang efektif (Astuti, 2017).

\section{Strategi Desain Instruksional}

Strategi ini dipakai oleh para pendidik yang fokus pada pembelajaran individual sebagai sasaran utama. Startegi kelompok ini, mendasarkan diri dari teori-teori belajar formal, dan berfokus pada pendekatan sistem untuk pembangunan materi pembelajaran seperti evaluasi formatif, uji coba, dan desain program berjenjang (Astuti, 2017). Secara umum strategi ini memiliki tiga tahapan yaitu tahap perencanaan, tahap implementasi dan tahap evaluasi.

\section{Strategi Partisipatori}

Dalam strategi partisipatori ini, prinsip-prinsip penting dalam mengorganisir kegiatan adalah kerja sama komunitas dan pertumbuhan pribadi (Astuti, 2017). Strategi ini melakukan pendekatan melalui pendidikan nonformal seperti pelatihan.

\section{Strategi Pemasaran}

Strategi ini tumbuh sebagai suatu strategi komunikasi yang sifatnya paling langsung dan terasa biasa dalam prinsip social marketing yakni 18 teknik pemasaran yang tidak hanya mencari keuntungan yang diperoleh dari sebuah penjualan, melainkan memfokuskan pada apa yang konsumen butuhkan dan inginkan dari suatu yang diproduksi oleh produsen (Astuti, 2017).

Strategi komunikasi pembangunan merupakan upaya penyebaran nilai-nilai pembangunan Nawacita dan SDGs yang merupakan sebuah inovasi karena dikemas dengan istilah dan pendekatan baru serta baru diputuskan untuk diterapkan di Indonesia secara luas dan serentak. Strategi komunikasi pembangunan untuk menyebarkan nilai-nilai Nawacita dan SDGs merupakan sebuah proses difusi inovasi yang dimaknai sebagai proses dimana suatu inovasi dikomunikasikan melalui saluran tertentu dalam jangka waktu tertentu diantara para anggota suatu sistem sosial (Istiati, 2016). Proses difusi inovasi dipengaruhi oleh empat unsur, yaitu: inovasi, saluran komunikasi, jangka waktu dan sistem sosial yang dapat dikaitkan dengan strategi komunikasi pembangunan yang dikemukakan oleh Academy for Educational Development (AED). Strategi yang didasarkan pada media yang dipakai menekankan pentingnya penggunaan saluran komunikasi yang tepat, strategi desain instruksional dan strategi partisipatori menekankan pentingnya pertimbangan jangka waktu dan sistem sosial serta 
strategi pemasaran yang menekankan pentingnya mengemas inovasi sebagai pengetahuan baru yang dapat diterima masyarakat.

\section{METODE PENELITIAN}

Penelitian ini menggunakan metode kualitatif deskriptif. Menurut Bogdan dan Tailor mendeskripsikan "metode kualitatif" sebagai prosedur penelitian yang menghasilkan data deskriptif berupa kata-kata tertulis atau lisan dari orang-orang dan perilaku yang diamati (Astuti, 2017). Dalam melakukan penelitian ini yang menjadi objek penelitian adalah strategi komunikasi pembangunan yang dilakukan oleh Pemkab Bojonegoro dalam menerapkan Nawacita dan SDGs dimensi people. Subjek penelitian adalah Kang Yoto selaku Bupati Kabupaten Bojonegoro periode 2008 - 2018. Teknik yang dipakai dalam menentukan informan adalah teknik purposif dimana Kang Yoto relevan dengan penelitian karena jabatan Kang Yoto sebagai seorang bupati. Data penelitian didapatkan dari pertanyaanpertanyaan yang berkaitan dengan strategi komunikasi pembangunan Pemkab Bojonegoro dalam menerapkan Nawacita untuk mencapai SDGs dimensi people. Pertanyaan-pertanyaan tersebut diajukan kepada Kang Yoto dalam wawancara yang dilakukan melalui voice note Whatsapp pada Senin, 16 Desember 2019 yang kemudian dikombinasikan dengan hasil dokumentasi dari berbagai literasi, media dan sumber. Hasil wawancara dan dokumentasi diolah melalui proes reduksi data, penyajian data dan menarik kesimpulan untuk mengetahui strategi komunikasi pembangunan yang digunakan Pemkab Bojonegoro.

\section{HASIL DAN PEMBAHASAN}

Kabupaten Bojonegoro pada tahun 2008-2018 dipimpin oleh Suyoto atau yang akrab dipanggil Kang Yoto. Selama memimpin, Kang Yoto fokus pada pada pembangunan yang disebut dengan Rencana Pembangunan Bojonegoro yang memiliki enam pilar pembangunan berkelanjutan. Enam pilar tersebut terdiri dari pilar ekonomi, pilar lingkungan hidup, pilar pembangunan manusia dan modal sosial, pilar kebijakan fiskal berkelanjutan, fiskal good government dan kemudian fiskal kepemimpinan transformatif. Rencana Pembangunan Bojonegoro dipadukan dan disinkronisasikan dengan Nawacita karena terdapat beberapa poin yang sama antara kedua program tersebut terutama dalam tema manusia, tema ekonomi, tema pembangunan pemerintahan yang hadir yang mencakup kemandirian pangan, kemandirian energi, kemandirian sosial, pemerintah yang hadir, good government dan infrastruktur.

“...saya sedang melaksanakan Rencana Pembangunan Bojonegoro dan kebetulan saja itu in line (dengan Nawacita). Misalnya kemandirian pangan, kemandirian energi, kemandirian sosial, pemerintah yang hadir, good government dan infrastruktur."

Selain Rencana Pembangunan Bojonegoro dan Nawacita, kehadiran Sustainable Development Goals (SDGs) dipertimbangkan Kang Yoto sebagai tools atau alat serta kerangka berfikir untuk mencapai tujuan-tujuan pembangunan berkelanjutan yang memang sudah dilakukan Kang Yoto sejak menjabat Bupati Bojonegoro pada tahun 2008. Dalam pelaksanaan SDGs, Kang Yoto menerapkan beberapa tujuan dan terdapat 14 tujuan SDGs yang sudah diratifikasi di Kabupaten Bojonegoro. Untuk menunjukkan komitmen Kang Yoto dalam melaksanakan SDG, Kang Yoto membuat indeks-indeks pelaksanaan SDGs dan pada Bulan Oktober 2016 Kang Yoto membuat Keputusan Bupati Bojonegoro Nomor 188/1171/KEP/412.11/2016 tentang Gugus Tugas Pelaksana Tujuan Pembangunan Berkelanjutan (Sustainable Development Goals/ SDGs) Kabupaten Bojonegoro.

"SDGs itu bagi saya adalah panduan, memberi kelengkapan alat, tool, untuk sasaran pembangunan di Kabupaten Bojonegoro dengan 17 tujuan. Maka, kalau tidak salah baru 14 atau 15 kami sudah meratifikasi SDGs di Bojonegoro dan itu kami membuat indeks-indeks SDGs-nya."

Kang Yoto memberikan perhatian lebih pada pembangunan manusia berlekanjutan yang disebut dengan dimensi people dalam SDGs. Untuk mewujudkan tujuan tersebut, Pemkab Bojonegoro menyediakan sarana kesehatan yang lebih baik dan dengan jumlah yang lebih banyak. Berdasarkan data pada tahun 2018, Kabupaten Bojonegoro memiliki 2053 fasilitas kesehatan yang tersebar di seluruh kecamatan yang terdiri dari Rumah sakit, puskesmas, pembantu, polindes, posyandu, pusling, dan apotik. Selain sektor kesehatan, Kang Yoto juga memberikan beasiswa pendidikan bagi seluruh anak yang ingin bersekolah mulai dari Raudlatul Athfal (RA) atau TK, SD, SMP bahkan SMA serta 
kuliah. Pemberian beasiswa ini berpengaruh pada angka partisipasi sekolah yang mencapai $100 \%$ untuk usia $7-12$ tahun mencapai, mencapai 95,61\% untuk 13 - 15 tahun dan mencapai 80,22\% untuk usia 16 - 18 tahun. Hingga tahun 2018, tercatat 222.761 murid yang sedang menjalankan pendidikan dari RA atau TK hingga SMA atau SMK. Jumlah murid tersebut bersekolah di 1635 fasilitas pendidikan yang tersebar di seluruh kecamatan di Kabupaten Bojonegoro.

Pemkab Bojonegoro membekali warganya dengan ketrampilan yang akan terpakai di dunia kerja dengan memperbanyak jumlah SMK. Hingga tahun 2018, terdapat 62 SMK dengan 22.836 murid yang diajar oleh 1332 guru. Selain SMK, ada pula 30 Pusat Kegiatan Belajar Masyarakat (PKBM) yang memberikan pendidikan non-formal serta pelatihan untuk 8.626 murid dengan 1765 tutor. PKBM adalah satuan pendidikan nonformal yang bertujuan untuk memberikan layanan pendidikan bagi masyarakat (Fauziah, 2009). Kabupaten Bojonegoro juga memiliki 68 lembaga kursus dengan 1966 murid yang ditangani oleh 235 tutor.

Rencana Pembangunan Bojonegoro, Nawacita dan SDGs merupakan inovasi pembangunan yang dikemas dengan istilah baru. Inovasi ini dikomunikasikan kepada masyarakat agar masyarakat memahami dan akhirnya mau terlibat secara aktif dalam proses pembangunan. Proses mengkomunikasikan inovasi ini dapat dilakukan melalui penerapan strategi komunikasi pembangunan yang menekankan pentingnya penggunaan saluran komunikasi, jangka waktu, karakteristik sistem sosial dan inovasi. Strategi komunikasi pembangunan dalam upaya mengkomunikasikan Nawacita dan SDGs yang dilakukan oleh Pemkab Bojonegoro adalah:

\section{Strategi yang Didasarkan pada Media yang Dipakai (Media Based Strategy)}

Strategi ini menekankan pada penggunaan saluran komunikasi yang tepat agar sesuai sasaran. Pemkab Bojonegoro menggunakan beberapa saluran komunikasi untuk menyebarkan Nawacita dan SDGs seperti media massa, media baru dan komunikasi antarpribadi.

Media massa yang dipakai Pemkab Bojonegoro adalah koran lokal dan nasional, televisi lokal seperti JTV dan B-One TV serta radio Pemkab Bojonegoro, Malowopati FM. Koran digunakan sebagai media komunikasi pembangunan karena menurut Kang Yoto, koran dapat terdokumentasi serta dapat dibuat versi online-nya. Selain koran, Pemkab Bojonegoro juga memakai saluran televisi lokal seperti JTV dan B-One TV. Namun penggunaan media televisi ini tidak terlalu intensif karena jumlah penonton yang tidak terlalu banyak.

Media massa yang dirasa paling efektif penggunaanya menurut Kang Yoto adalah radio Pemkab Bojonegoro, Radio Malowopati FM di frekuensi 95.8 serta radio lokal lain yang rutin menyiarkan acara Cakrawala Pagi mulai dari pukul $6-8$ pagi. Radio memiliki peluang untuk menjangkau pendengar secara lebih luas, dan dapat diakses secara lebih murah (Kifli, 2007). Dalam siaran radio tersebut, Pemkab Bojonegoro memberikan panduan, berita serta memberi akses kepada masyarakat untuk bertanya atau menyampaikan keluhan kepada pejabat Pemkab Bojonegoro lewat pesan singkat ke nomor 0821143212958.

"Televisi lokal yang ada adalah JTV dan biasanya B-One kita lakukan tapi tidak terlalu intensif karena memang penontonnya juga tidak terlalu banyak. Dan juga radio juga jauh lebih efektif..."

Penggunaan berbagai media massa ini dipakai sebagai media sosialisasi pemerintah untuk mensinkorinasasikan semuanya (Rencana Pembangunan Bojonegoro, Nawacita, SDGs) menjadi bagian yang integral, sinergis untuk pembangunan yang akan berdampak kepada semua rakyat Bojonegoro. Keterbukaan informasi ini bisa diakses warga Bojonegoro dan masyarakat umum sebagai bukti Pemkab Bojonegoro adalah pemerintahan yang terbuka.

“...Bojonegoro menggunakan media online, offline dan kemudian bahkan juga koran di Bojonegoro, itu kita sosialisasikan bagaimana kita mencoba melakukan sinkronisasi semuanya menjadi bagian yang integral, sinergis untuk pembangunan."

Media baru juga dipakai Kang Yoto untuk mengkomunikasikan program-programnya. Namun penggunaan media baru seperti media sosial maupun website tidak terlalu diprioritaskan karena $95 \%$ rakyat Bojonegoro, kepala desa dan perangkat desa masih belum menggunakan media sosial. Media 
sosial yang umumnya digunakan di Bojonegoro adalah Facebook namun menurut Kang Yoto penggunaan Facebook tidak efektif karena didominasi akun-akun palsu atau akun para pendatang yang ingin saling berinteraksi. Namun untuk keterbukaan informasi bagi publik, Kang Yoto tetap menggunakan media sosial seperti Twitter (@pemkba_bjn) dan Facebook (Pemerintah Kabupaten Bojonegoro) yang cukup rutin dipakai untuk membagikan kegiatan Pemkab Bojonegoro kepada publik.

“...tidak terlalu efektif karena pengguna Facebook itu banyak yang fake account jadi kami tidak bisa mengandalkan untuk media ini betul betul akan menjangkau kepada masyarakat sasaran. Dan mayoritas warga yang menjadi sasaran belum menggunakan media sosial, yang menggunakan itu baru kaum milenial dan kaum terpelajar."

Selain media sosial, penggunaan website juga penting bagi Kang Yoto untuk melaporkan kepada publik sejauh mana Pemkab Bojonegoro telah melaksanakan pemerintahannya. Melalui website www.bojonegoro.go.id Pemkab Bojonegoro menyediakan menu seperti Berita, Agenda, Regulasi dan Media Center yang bisa diakses masyarakat. Selain itu, Bojonegoro juga menyediakan Layanan Aspirasi dan Pengaduan Online Rakyat (LAPOR!) yang dapat diakses lewat website www.lapor.go.id, SMS 1708, Twitter (@lapor1708) dan aplikasi Android. LAPOR! adalah layanan yang dikelola Kementrian Pendayagunaan Aparatur Negara dan Reformasi Birokrasi (Kementrian PANRB) dimana masyarakat dapat mengadukan dari manapun dan jenis apapun untuk disalurkan kepada penyelenggara yang berwenang seperti Pemkab Bojonegoro.

Penggunaan media massa dan media baru oleh Pemkab Bojonegoro diimbangi dengan komunikasi antarpribadi untuk mengkomunikasikan program yang berkaitan dengan Nawacita dan SDGs melalui dialog publik yang dilakukan setiap Jumat dimana para pejabat Pemkab Bojonegoro langsung bertemu dengan para warga untuk saling berkomunikasi. Ketika melakukan kunjungan, Kang Yoto juga melakukan dialog langsung dengan para warga tanpa memberi penekanan bahwa program yang dijalankannya berkaitan dengan Nawacita dan SDGs. Hal ini karena Nawacita dan SDGs hanya penamaan di level pemerintahan dan warga cukup mengerti ada istilah-istilah tersebut. Warga lebih menaruh perhatian pada pembangunan yang solutif dan relevan dengan permasalahan yang mereka hadapi. Kang Yoto juga membagikan nomor pribadinya agar para warga bisa langsung mengirim pesan singkat kepadanya terkait keluhan-keluhan para warga.

“...nomor handphone saya bagikan ke masyarakat dan semua orang tahu nomor saya, bisa sms saya. Itu ternyata bisa jadi cara yang cukup efektif untuk saling berkolaborasi, bersinergi dengan masyarakat."

Dalam menerapkan komunikasi antarpribadi, Kang Yoto juga memperkuat social capital dengan membentuk Wali Amanat melalui Perbup Nomor 55 Tahun 2014 tentang Pembentukan Wali Amanat Desa. Wali Amanat Desa adalah kumpulan tokoh masyarakat, tokoh budaya, kelompok difabel dan lain lain yang bertugas untuk mengawal penyelenggaraan pemerintahan, pelaksanaan pembangunan, pembinaan kemasyarakatan dan pemberdayaan masyarakat desa. Berdarkan pengertian tersebut Wali Amanat menggambarkan keberagaman di desa yang diisi oleh berbagai latar belakang serta kredibel sehingga memiliki kekuatan moral untuk mengawasi pemerintah desa. "Wali Amanat merupakan bagian dari social capital dimana semua pihak yang menggambarkan diversity ada di situ dan dia adalah orang-orang yang kredibel di desa."

\section{Strategi Desain Instruksional}

Strategi desain instruksional adalah strategi yang memberikan pelatihan atau kegiatan dengan pihakpihak yang terlibat dan melalui tiga tahapan yaitu perencanaan, implementasi dan evaluasi dalam jangka waktu tertentu yang diperuntukkan pada masyarakat. Strategi ini dilakukan Pemkab Bojonegoro dengan memberikan pelatihan dan pendidikan vokasional bagi warga Bojonegoro untuk meningkatkan daya saing secara nasional.

Pendidikan vokasional yang diberikan Pemkab Bojonegoro adalah perbengkelan kendaraan, mengelas, listrik, pengolahan makanan dan pengolahan industri pertanian. Dinas Tenaga Kerja dan Transmigrasi Pelaksana Teknis Balai Latihan Kerja Bojonegoro memberikan pelatihan secara gratis melalui proses seleksi. Fasilitas yang didapat oleh peserta pelatihan antara lain adalah modul, seragam, sertifikat dan makan siang. 


\section{Strategi Pemasaran}

Strategi pemasaran adalah strategi yang dipakai untuk menghasilkan produk yang sesuai dengan kebutuhan serta keinginan konsumen. Dalam hal pembangunan Pemkab Bojonegoro, konsumen yang dimaksud adalah warga Bojonegoro. Kang Yoto menggunakan strategi pemasaran dengan mengemas nilai-nilai pembangunan dengan pendekatan budaya, seperti festival budaya agar lebih mudah diterima warga Bonegoro. Festival kebudayaan dilakukan Kang Yoto untuk memadukan alam sekaligus manusia agar dapat bersinergi dan berhubungan dengan baik. Festival yang diselenggarakan antara lain Jazz Bengawan, Festival Bengawan, Festival Belimbing, Pawai Adat dan Religi, Festival Bougen, Festival Reog Jalanan dan Festival Seblak Sampur. “...saya bikin berkah acara-acara yang berbau budaya pun kami lakukan untuk terus memperkuat basis basis socio capital.”

Jazz Festival adalah salah satu festival besar yang diselenggarakan Pemkab Bojonegoro dengan melibatkan berbagai artis jazz serta artis dari genre lain untuk memberi hiburan kepada warga Bojonegoro yang dilakukan di pinggiran Sungai Bengawan Solo. Jazz Festival digunakan sebagai pendekatan ke masyarakat untuk tetap melestarikan dan merawat Sungai Bengawan Solo yang sering menyebabkan banjir karena perilaku warga. Sebelum acara dimulai, Kang Yoto dan pejabat kabupaten yang lain serta para warga melakukan kegiatan tanam pohon. Selain Jazz Festival ada juga Festival Bengawan yang memiliki misi sama yaitu agar masyarakat ingin mendekatkan diri dengan Bengawan Solo. Dalam festival tersebut warga berlomba untuk menghias dan menggerakkan perahu hingga garis akhir untuk menentukan juara. Selain itu, ada juga Festival Belimbing yang dilaksanakan setiap Bulan November setiap tahun untuk memperingati hari jadi Kabupaten Bojonegoro. Festival Belimbing ini dimulai saat warga merubah kawasan banjir di pinggir Bengawan Solo yang awalnya ditanami palawija menjadi perkebunan belimbing. Perkebunan belimbing banyak dikunjungi para wisatawan terutama saat banjir datang karena para wisatawan akan memetik belimbing dari pohonnya menggunakan perahu. Festival Belimbing dilakukan dengan cara membuat gunungan belimbing yang diperebutkan warga yang kemudian dihibur dengan rangkaian penampilan reog serta pertunjukkan lain.

\section{Strategi Partisipatori}

Strategi partisipatori memanfaatkan kerjasama komunitas yang memiliki pengalaman sesuai dengan pembangunan yang ingin dikomunikasikan dalam jangka waktu tertentu. Strategi ini melakukan pendekatan melalui pendidikan nonformal seperti pelatihan yang memungkinkan komunitas atau lembaga lain untuk saling bertukar informasi. Strategi ini juga dipakai oleh Pemkab Bojonegoro untuk mengkomunikasikan program-programnya yang selaras dengan Nawacita dan SDGs.

Beberapa komunitas, civil society, Lembaga Swadaya Masyarakat (LSM) serta beberapa universitas seperti Universitas Airlangga, Universitas Islam Negeri Surabaya, Universitas Gadjah Mada dan Institut Pertanian Bogor telah melakukan beberapa pelatihan dan melakukan pembangunan di Bojonegoro melalui kegiatan Praktek Kerja Lapangan dan pelatihan-pelatihan yang ditujukan bagi warga Bojonegoro. Keterlibatan berbagai pihak dalam upaya pembangunan Bojonegoro diberikan wadah oleh Pemkab Bojonegoro melalui Open Government Partnership (OGP). Melalui OGP, Pemkab Bojonegoro memberikan laporan yang terbuka terkait kerjasama yang dilakukan dengan komunitas, akademisi, dan sektor bisnis.

"Di tempat kami kan OGP, OGP itu kan partnership. Partnership itu ada empat yaitu akademisi, businessman, kemudian civil society dan community atau masyarakat bersama dengan pemerintah. Kebetulan di Bojonegoro kami bikinkan platformnya."

Pelaksanaan SDG's berhasil menurunkan proporsi penduduk miskin dari 28,12 persen pada tahun 2003 menjadi 14,88 persen pada tahun 2016. Sekitar 67,65 persen Indikator SDG's dari total indikator yang mengukur target SDG's untuk Kabupaten/Kota telah berhasil di capai oleh Kabupaten Bojonegoro, dan sekitar 17,65 persennya menuju arah pencapaian target (Sastryawanto, 2018). Pemkab mengkomunikasikan nilai-nilai pembangunan Nawacita dan SDGs dengan baik sehingga indeks berbagai sekor di Kabupaten Bojonegoro mengalami peningkatan yang signifikan. Keberhasilan Bojonegoro dalam menerapkan SDGs karena Pemkab Bojonegoro melakukan pendekatan yang mudah diterima masyarakat yaitu dengan pendekatan budaya serta menggunakan saluran komunikasi yang tepat. Namun pendekatan-pendekatan ini tidak dilakukan secara konsisten 
dan mengalami perubahan saat bupati baru menjabat karena memiliki kepemimpinan yang berbeda dari bupati sebelumnya.

Tabel 1. Baseline data sesuai perspektif SDGs di Bojonegoro, 2018

\begin{tabular}{|c|c|c|c|c|}
\hline \multirow[t]{2}{*}{ No. } & \multirow[t]{2}{*}{ Tujuan SDGs } & \multirow[t]{2}{*}{ Variabel } & \multicolumn{2}{|c|}{ Tahun } \\
\hline & & & 2008 & September 2016 \\
\hline 1. & Menghapus Kemiskinan & $\begin{array}{l}\text { Presentase Penduduk } \\
\text { Miskin }\end{array}$ & $>28 \%$ & $<14,00 \%$ \\
\hline 2. & Mengatasi Kelaparan & Pola Pangan Harapan & $61 \%$ & $72,1 \%$ \\
\hline 3. & Kesehatan \& Kesejahteraan & $\begin{array}{l}\text { Balita Kurang Gizi } \\
\text { Kematian Bayi }\end{array}$ & $\begin{array}{r}14,22 \% \\
32 / 1000 \text { kelahiran } \\
\text { hidup }\end{array}$ & $\begin{array}{r}5,02 \% \\
16,01 \%\end{array}$ \\
\hline 4. & Pendidikan Bermutu & $\begin{array}{l}\text { APK SMA (terkait } \\
\text { wajar } 12 \text { tahun) APM } \\
\text { SMA }\end{array}$ & $53,86 \%$ & $86,27 \%$ \\
\hline 5. & Kesetaraan Gender & $\begin{array}{l}\text { Indeks Pembangunan } \\
\text { Gender (IPG) } \\
\text { Indeks Pemberdayaan } \\
\text { Gender (IDG) }\end{array}$ & $\begin{array}{l}53,57 \% \\
50,34 \%\end{array}$ & $\begin{array}{l}89,24 \% \\
84,45 \%\end{array}$ \\
\hline 6. & $\begin{array}{l}\text { Akses Air Bersih dan } \\
\text { Sanitasi }\end{array}$ & $\begin{array}{l}\text { Akses Air Bersih } \\
\text { Akses Sanitasi Open } \\
\text { Defecation Free (ODF) }\end{array}$ & $\begin{array}{r}57,85 \% 63,12 \% \\
0\end{array}$ & $\begin{array}{r}79,64 \% 85,61 \% \\
198 \text { Desa }\end{array}$ \\
\hline 7. & Energi Bersih & $\begin{array}{l}\text { Listrik Tenaga Surya } \\
\text { (collar cell) }\end{array}$ & 2 dusun & 11 dusun $(726 \mathrm{KK})$ \\
\hline 8. & Pekerjaaan Layak & $\begin{array}{l}\text { Tingkat Pengangguran } \\
\text { Terbuka (TPT) }\end{array}$ & $5,92 \%$ & $3,10 \%$ \\
\hline 9. & $\begin{array}{l}\text { Infrastruktur dan Industri } \\
\text { (Sesuai) }\end{array}$ & $\begin{array}{l}\text { APBD } \\
\text { Kondisi Jalan Baik } \\
\text { Kondisi } \\
\text { Kondisi Jembatan Baik }\end{array}$ & $\begin{array}{r}\text { Rp. } 892 \mathrm{M} \\
20 \% \\
37 \%\end{array}$ & $\begin{array}{r}3,4 \mathrm{~T} \\
88,57 \% \\
84,59 \%\end{array}$ \\
\hline 10. & Mengurangi Ketimpangan & Index Gini & 0,32 & 0,24 \\
\hline 11. & Kota Berkelanutan & $\begin{array}{l}\text { Penataan Tata Ruang } \\
\text { Kecamatan } \\
\text { Tata Ruang Desa } \\
\text { Aplikasi E-Gov }\end{array}$ & $\begin{array}{r}0 \mathrm{kec} \\
8 \\
\text { Aplikasi }\end{array}$ & $\begin{array}{lr} & 4 \mathrm{kec} \\
8 \text { Desa } & 57 \\
& \text { Aplikasi }\end{array}$ \\
\hline 12. & $\begin{array}{l}\text { Konsumsi Produksi } \\
\text { Bertanggungjawab }\end{array}$ & $\begin{array}{l}\text { Prosentase ketersediaan } \\
\text { energi pangan }\end{array}$ & 2,102/kkal /kap/hr & 5,188 \\
\hline 13. & Perubahan Iklim & $\begin{array}{l}\text { Indeks Kualitas } \\
\text { Lingkungan Hidup }\end{array}$ & 11,71 & 63,97 \\
\hline 14. & $\begin{array}{l}\text { Ekosistem Darat } \\
\text { Terlindungi }\end{array}$ & $\begin{array}{l}\text { RTH } \\
\text { Desa dengan Tanggap } \\
\text { Mitigasi Bencana }\end{array}$ & $\begin{array}{r}19,71 \mathrm{Ha} \\
0 \text { Desa }\end{array}$ & $\begin{array}{r}27,74 \mathrm{Ha} \\
12 \mathrm{Desa}\end{array}$ \\
\hline 15. & Perdamaian & $\begin{array}{l}\text { Presentasi Fasilitasi } \\
\text { Penanganan Konflik }\end{array}$ & $43 \%$ & $100 \%$ Tertangani \\
\hline 16. & Kemitraan & $\begin{array}{l}\text { Pembinaan terhadap } \\
\text { LSM, Ormas dan OKP }\end{array}$ & 17 LSM & $\begin{array}{r}4 \text { Jenis Kegiatan } \\
\text { LSM } \\
\end{array}$ \\
\hline
\end{tabular}

\section{KESIMPULAN}

Strategi komunikasi pembangunan dalam menerapkan Nawacita dan Sustainable Development Goals (SDGs) yang diterapkan Pemerintah Kabupaten (Pemkab) Bojonegoro dapat diikuti oleh daerah lain dengan menyesuaikan kondisi masyarakatnya. Kondisi masyarakat harus diperhatikan untuk mengetahui saluran komunikasi yang tepat agar nilai-nilai Nawacita dan SDGs dapat diterima masyarakat dengan baik. Selain itu, pengemasan nilai-nilai Nawacita dan SDGs juga dapat dipadukan dengan budaya-budaya yang masih mengakar di masyarakat serta dikemas dengan istilah yang mudah dipahami.

Strategi yang didasarkan pada media yang dipakai (media based strategy), strategi partisipatori, strategi pemasaran dan strategi desain instruksional yang disesuaikan dengan kondisi masyarakat serta dikemas dengan nilai budaya terbukti efektif dalam mengajak masyarakat Bojonegoro untuk aktif dalam proses pembangunan yang didasarkan pada nilai-nilai Nawacita dan SDGs. Strategi komunikasi 
pembangunan yang tepat berhasil menurunkan angka kemiskinan serta peningkatan pencapaian indeks SDGs di Kabupaten Bojonegoro.

\section{DAFTAR PUSTAKA}

Arianto, Z. (2019). Upaya Pemerintahan Joko Widodo dalam Mendorong Implementasi Sustainable Development Goals di Indonesia.

Astuti, R. (2017). Strategi Komunikasi Pembangunan dalam Mempertahankan Pasar Tradisional Sentral Benteng di Kabupaten Kepulauan Selayar. Universitas Islam Negeri (UIN) Alauddin Makassar.

Fajri, C., Mawadati, S., \& Yudhana, A. (2018). Komunikasi Pembangunan Pemerintah Kulon Progo dalam Memberikan Pemahaman kepada Masyarakat Terkait Pembangunan New Yogyakarta Internasional Airport. Jurnal Komunikator, 10(2). https://doi.org/http://dx.doi.org/10.18196/jkm.101012

Fauziah, P. Y. (2009). Pusat Kegiatan Belajar Masyarakat ( Pkbm ) Sebagai Wadah Pemberdayaan. In Undang-Undang Nomor 11 Tahun 2009.

Guha, J., \& Chakrabarti, B. (2019). Achieving the Sustainable Development Goals ( SDGs ) through decentralisation and the role of local governments : a systematic review. Commonwealth Journal of Local Governance, 22, 1-21. https://doi.org/https://doi.org/10.5130/cjlg.v0i22.6855

Hoelman, M. B., Parhusip, B. T. P., Eko, S., Bahagijo, S., \& Santono, H. (2016). Sustainable Development Goals-SDGs Panduan Untuk Pemerintah Daerah (Kota dan Kabupaten) dan Pemangku Kepentingan Daerah.

ICLEI. (2015). From MDGs to SDGs : What are the Sustainable Development Goals ? (Issue 01).

Istiati, F. (2016). Difusi Inovasi Dalam Kegiatan Komunikasi Pembangunan (Studi DeskriptifKualitatif Terhadap Program Bantuan Bibit Gratis oleh Persemaian Permanen Balai Pengelola Daerah Aliran Sungai dan Hutan Lindung Serayu Opak Progo Yogyakarta pada Masyarakat Desa Gading. Universitas Islam Negeri Sunan Kalijaga Yogyakarta.

Kestin, T., Belt, M. van den, Denby, L., Ross, K., Thwaites, J., \& Hawkes, M. (2017). Getting Started with The SDGs in Universities A Guide For Universities, Higher Education Institutions, and The Academic Sector.

Kifli, G. C. (2007). Strategi Komunikasi Pembangunan Pertanian pada Komunitas Dayak di Kalimantan Barat. Forum Penelitian Agro Ekonomi, 25, 117-125. https://doi.org/10.21082/fae.v25n2.2007.117-125

Lisbet. (2013). Pencapaian Millenium Development Goals (MDGs) di Indonesia Melalui Kerjasama Internasional. Politica, 4(1), 33-48. https://doi.org/10.1080/13629395.2014.1001631

Morita, K., Okitasari, M., \& Masuda, H. (2019). Analysis of national and local governance systems to achieve the sustainable development goals : case studies of Japan and Indonesia. Sustainability Science, 0123456789. https://doi.org/10.1007/s11625-019-00739-z

Nurdin, A. (2013). Strategi Komunikasi dalam Sosialisasi Pembangunan Jembatan Selat Sunda di Propinsi Banten dan Lampung.

Panuluh, S., \& Fitri, M. R. (2016). Briefing Paper 02 Perkembangan Pelaksanaan Sustainable Development Goals ( SDGs ) di Indonesia (Issue September).

Reddy, P. S. (2016). Localising the sustainable development goals ( SDGs ) The role of Local Government in context. African Journal of Public Affairs, 9(2), 1-15.

Sastryawanto, H. (2018). Analisa Sustainable Development Goal's Kabupaten Bojonegoro Tahun 2017. Jurnal Ilmiah Sosio Agribis, 17(1), 47-52. https://doi.org/http://dx.doi.org/10.30742/jisa.v17i1.381

Sudagung, A. D., Putri, V., Sasiva, I., \& Olifiani, L. P. (2019). Upaya Indonesia Mencapai Target Sustainable Development Goals Bidang Pendidikan di Kecamatan Sekayam Kabupaten Sanggau Kalimantan Barat (2014-2019). Jurnal Polinter Prodi Ilmu Politik FISIP, 5(1), 1-27.

Surahmi, A., \& Farid, H. M. (2018). Strategi Komunikasi Dalam Meningkatkan Partisipasi Masyarakat Terhadap Pembangunan di Kecamatan Duampanua Kabupaten Pinrang. Jurnal Komunikasi Kareba, 7(2), 232-239. https://doi.org/http://dx.doi.org/10.31947/kareba.v7i2.6959

Tahoba, A. E. P. (2011). Strategi Komunikasi Dalam Program Pengembangan Masyarakat (Community Development) Kasus Program Community Development pada Komunitas Adat Terkena Dampak Langsung Proyek LNG Tangguh di Sekitar Teluk Bintuni Kabupaten Teluk Bintuni Provinsi Papua Barat. Program Studi Agribisnis, Fakultas Pertanian Dan Teknologi Pertanian, Universitas Papua, 187-197. 
Wahyuningsih, D. (2016). Upaya Pencapaian Target Tujuan Pembangunan Berkelanjutan (TPB) Indonesia. In Disampaikan pada Kegiatan Jaring Masukan Kontribusi WIPO untuk Pencapaian SDGs.

Wibowo, C. T. S., Hafidhuddin, D., \& Agung, S. S. (2011). Strategi Pengembangan Komunikasi Massa dalam Mendukung Pembangunan Pertanian dengan Pendekatan Jati Diri Bangsa yang Berorientasi pada Budaya. Jurnal Komunikasi Pembangunan, 9(2), 39-52.

Wijaya, I. S. (2015). Perencanaan dan Strategi Komunikasi dalam Kegiatan Pembangunan. Jurnal Lentera, XVIII(1), 53-61. https://doi.org/https://doi.org/10.21093/1j.v17i1.428 